\title{
LA SOCIOLOGÍA DEL SIGLO XX
}

\author{
Emilio Lamo de Espinosa
}

Universidad Complutense de Madrid

\begin{abstract}
RESUMEN
El siglo XX confirma la definitiva institucionalización (académica y científica) de la sociología como un conocimiento público legitimado, algo que no habían conseguido ni los pioneros del siglo XVIII ni los grandes creadores del XIX (de Comte a Spencer, pasando por Tocqueville o Marx). Partiendo de los datos recopilados por la ISA en su Congreso de Montreal, este trabajo pretende responder a la pregunta por los textos más importantes de la sociología del siglo pasado, aprovechando para hacer una periodificación del desarrollo del pensamiento sociológico en el marco de una sociología de la sociología. Se repasan así a los grandes institucionalizadores de comienzos del XX, a los compiladores que, entre 1920 y 1968, van a conformar dos grandes escuelas (funcionalista y marxista) antagónicas en mucho pero convergentes en creencias fundamentales, al giro constructivista o hermenéutico de la sociología a partir de 1968 (aún dominante), y el regreso posterior a la Gran Teoría que se solapa con el más reciente análisis de la sociedad post- (industrial, burguesa o moderna).
\end{abstract}

1 Agradezco a Editorial Cátedra y al profesor Manuel Garrido su permiso para publicar este texto, que aparecerá próximamente en una obra colectiva editada por ambos y titulada El legado filosófico y científico del siglo XX. El estilo de la obra, más ensayístico que académico, he preferido respetarlo en esta pre-publicación. Doy las gracias también a Julio Carabaña y a Javier Noya por las observaciones y comentarios que hicieron a versiones preliminares de este trabajo. 
$Y$ confieso que prefiero un conocimiento cierto aunque imperfecto, incluso si deja muchas cosas indeterminadas e impredecibles, a la pretensión de un conocimiento exacto que con much a probabilidad es falso.

(Von HayeK, "The Pretense of Knowledge», en New Studies, Routledge and Kegan Paul, London, 1978, p. 29.)

If a thing is not recognized as true, then it does not function as true in the community.

(G. H. Mead, Movements of Thought in the Nineteenth Century, University of Chicago Press, 1936, p. 29.)

\section{LA SOCIOLOGÍA DE LA SOCIOLOGÍA: LOS DATOS DE UNA ENCUESTA}

A nadie sorprenderá que, tratándose de un gremio de científicos sociales como es el de los sociólogos, la pregunta por los pensadores más importantes del siglo XX haya sido objeto de tratamiento empírico de modo que podemos contestarla apoyándonos no en impresiones personales, sino a través de los resultados de una encuesta. Y espero que a nadie sorprenda este proceder cuantitativo, un producto más de la sociología aplicada a la propia sociología, pues en esta ciencia (o saber, disciplina o arte, que de todo hay) se dan dos circunstancias que la hacen especialmente reflexiva (si se quiere decir positivamente) o narcisista (si se valora negativamente).

La primera es que es un saber que no puede seguir el consejo clásico de Whitehead: una ciencia que no olvida a sus clásicos está perdida. Antes bien, como las humanidades, con las que está más emparentada de lo que cree y desea, y a diferencia de la ciencia tout court, la sociología regresa una y otra vez a sus clásicos, si bien éstos (como en las humanidades) varían en el tiempo y su elenco se reconstruye al tiempo que avanza (o al menos cambia) la sociología. La segunda razón de la proclividad reflexiva de la sociología es que ésta, al abordar su historia intelectual (o la historia del pensamiento en general), no puede hacerlo al modo clásico como simple historia de las ideas. Pues si algo enseña la sociología es que (por decirlo en el lenguaje clásico de Marx) no es la conciencia lo que determina el ser social, sino éste quien determina la conciencia. O, por decirlo al modo usual de la sociología del conocimiento, todo conocimiento está socialmente determinado, lo que vale no sólo para el conocimiento de sentido común o cotidiano, sino también, faltaría más, para el científico, ya sea éste sobre la sociedad o sobre la naturaleza. Si como científicos partimos de la hipótesis irrenunciable de que todo cuanto existe tiene causa (salvo, eventualmente, Dios, única causa no causada), y si buscar esas causas es justamente la tarea de la ciencia, ¿por qué razón íbamos a excluir a la ciencia de ese principio 
de causalidad universal para hacer de ella una causa no causada, un Dios implícito? Lo que nos lleva a la conclusión de que la sociología, al abordar el pensamiento (y, en primer lugar, el propio), no puede dejar de indagar las condiciones sociales de su producción, es decir, no puede no hacer sociología del conocimiento y, por lo tanto, sociología de la sociología. Y de ahí el carácter inevitablemente reflexivo de la sociología cuando se estudia a sí misma.

Una reflexividad que no es específica ni única, pues no debemos exagerar. Cierto que no podemos pensar en una física de la física, pero la reflexividad es siempre posible en las ciencias sociales. Así, la economía de la economía, a pesar de su escaso desarrollo (lo que dice mucho sobre la capacidad autocrítica de los diversos gremios científicos), tiene pleno sentido, probablemente más del que se piensa, y sus resultados serían de enorme interés y no poco sorprendentes. Como tiene también pleno sentido la ciencia política de la ciencia política, o incluso la psicología de la psicología. O como lo tienen también sus vertientes cruzadas; por ejemplo, ¿por qué no una economía de la sociología o de la psicología? En todo caso, y aun siendo posibles, no han adquirido la misma solera o tradición que la sociología de la sociología, rama sólida y constituida desde hace décadas y que, en este aspecto, se asemeja más a la historia de la historia, bien conocida hace tiempo como historiografía.

Sirva esto como introducción a la introducción de este trabajo en el que, como adelanté, voy a exponer los resultados de una encuesta que responde, justamente, a la pregunta que nos hemos formulado: cuáles son los sociólogos más relevantes del siglo XX. Con ocasión del XIV Congreso de Sociología Mundial de Montreal de 1998, dedicado justamente a evaluar críticamente la herencia de la sociología del siglo XX, la International Sociological Association (ISA) preparó una encuesta con objeto de determinar los top ten de la sociología del siglo XX. Para ello se solicitó de los 2.785 miembros de la ISA, sin duda una muestra ad hoc pero representativa de la sociología mundial, que mencionaran los cinco libros de sociología publicados en el siglo XX que habian sido más influyentes en su trabajo como sociólogos. La pregunta excluía, pues, a la sociología del XIX, si bien no pocas de las respuestas obviaron este límite temporal mencionando, por ejemplo, textos decimonónicos de Durkheim o incluso de Marx (sin duda republicados en el siglo XX). Pero la pregunta tenía el acierto de indagar no los libros más importantes o los más conocidos, sino aquellos que habían tenido mayor incidencia en el trabajo práctico de los sociólogos entrevistados, y creo por ello que el resultado de esta encuesta, a pesar de sus evidentes limitaciones ${ }^{2}$, es valioso y hace aflorar una importante visión de la historia de la sociología del siglo XX desde la perspectiva de finales de siglo. De modo que, aunque este trabajo irá bastante más allá de los datos de esta encuesta, sí parecía inevitable comenzar con ella.

${ }^{2}$ No tantas si se toma en consideración que el objeto de la encuesta es bien simple, obtener una relación jerarquizada de obras, y no se pretende someter tales datos a análisis cuantitativos ulteriores. 
Es interesante señalar de entrada cuál es la lengua en la que habían estudiado los sociólogos entrevistados pues, sin duda, ese sesgo debería afectar (luego veremos en qué medida) a la eventual selección de autores. Pues bien, como era de esperar, dos de cada tres (el 65,3\%) lo hicieron en inglés, idioma que es, como en tantos otros campos, la lingua franca de la mayoría de los sociólogos, si no la lengua nativa. El alemán y el francés, con un escaso $18 \%$ en cada caso, se disputan a mucha distancia la segunda posición, seguidos, también a mucha distancia, por el español $(7,4 \%)$, el holandés $(5,1 \%)$, el italiano $(4,7 \%)$ y otros (portugués, sueco, ruso y japonés). El predominio de la lengua inglesa en la formación de los sociólogos de finales del siglo XX es, pues, muy marcado. No olvidemos que la comunidad sociológica más voluminosa es, sin duda, la norteamericana, y ello al menos desde mediados del siglo pasado.

Pues bien, el resultado de la citada encuesta aparece reflejado en el cuadro adjunto. Aunque la ISA publicó no los diez primeros, sino nada menos que los mil textos citados alguna vez con al menos un voto, recojo sólo aquellos que tienen cinco o más menciones, lo que da una lista de 71 obras importantes del siglo XX. De todas ellas, sólo tres recibieron más de 50 votos, 15 más de 20, y 30 diez o más menciones. Considerando que al menos mil textos recibieron algún voto, el resultado que se ofrece a continuación, los 71 libros con al menos cinco votos, da un conjunto relativamente compacto. Lo que me propongo es comenzar con el análisis de los datos para, a partir de ellos, ir contextualizando (sintéticamente) los resultados, en un ejercicio de sociología del conocimiento de la sociología del siglo XX.

\section{INTERNATIONAL SOCIOLOGICAL ASSOCIATION LIBROS DEL SIGLO XX XIV CONGRESO MUNDIAL DE SOCIOLOGÍA Montreal, 1998}

\begin{tabular}{cccc}
\hline Autor & Titulo & Votos & $T / E$ \\
\hline
\end{tabular}

\section{LOS DIEZ PRIMEROS}

1 Weber, Max

2 Mills, Charles Wright

3 Merton, Robert K.

4 Weber, $M$.

5 Berger, P. L., y Luckmann, T.

6 Bourdieu, Pierre

7 Elias, Norbert

8 Habermas, Jürgen

9 Parsons, Talcott

10 Goffman, Erving
Economía y sociedad

La imaginación sociológica

Teoria y estructura social

La ética protestante y el espiritu del capitalismo

La construcción social de la realidad

La distinción

El proceso de civilización

La teoría de la acción comunicativa

La estructura de la acción social

La presentación del si mismo en la vida cotidiana

$\begin{array}{ll}95 & T \\ 59 & T \\ 52 & T \\ & \\ 47 & E \\ 45 & T \\ 43 & E \\ 30 & E \\ 29 & T \\ 28 & T \\ & \\ 25 & T\end{array}$


CON MÁS DE DIEZ MENCIONES

11 Mead, George Herbert

12 Parsons, Talcott

13 Durkheim, Émile

14 Giddens, Anthony

15 Wallerstein, Immanuel

16 Foucault, Michel

17 Kuhn, Thomas S.

18 Simmel, Georg

19 Beck, Ulrich

20 Braverman, Harry

21 Adorno, Theodor W., y Horkheimer, Max

22 Gramsci, Antonio

23 Coleman, James Samuel

24 Habermas, Jürgen

25 Moore, B.

26 Polanyi, Karl

27 Blau, Peter Michael, y Duncan, Otis Dudley

28 Gouldner, Alvin W.

29 Luhmann, Niklas

30 Mannheim, Karl
Espíritu, persona y sociedad

23

El sistema social

Las formas elementales de la vida religiosa

La constitución de la sociedad

El moderno sistema mundial

Vigilar y castigar

La estructura de las revoluciones científicas

Sociología

La sociedad del riesgo

Trabajo y capital monopolista

Dialéctica de la Ilustración

Cuadernos de cárcel

Fundamentos de la teoría social

Conocimiento e interés

Los orígenes sociales de la dictadura y la democracia

La Gran Transformación

La estructura ocupacional americana

La crisis de la sociología occidental

El sistem social

Ideología y Utopía
$23 \mathrm{~T}$

$22 \mathrm{~T}$

$21 \mathrm{~T}$

$21 \quad \mathrm{E}$

$17 \quad \mathrm{E}$

$14 \mathrm{~T}$

$14 \mathrm{~T}$

$13 \mathrm{~T}$

13 E

$12 \mathrm{~T}$

$12 \mathrm{~T}$

$11 \mathrm{~T}$

$11 \mathrm{~T}$

$11 \quad \mathrm{E}$

$11 \quad \mathrm{~T}$

$10 \quad \mathrm{E}$

$10 \mathrm{~T}$

$10 \mathrm{~T}$

$10 \mathrm{~T}$

\section{CON CINCO O MÁS MENCIONES}

31 Becker, Howard S.

32 Marx, Karl

33 Olson, Mancur

34 Durkheim, Émile

35 Durkheim, Émile

36 Garfinkel, Harold

37 Goffman, Erving

38 Lipset, Seymour Martin

39 Mills, Charles Wright

40 Bourdieu, Pierre

41 Cardoso, Fernando Henrique, y Faletto, Enzo

42 Dahrendorf, R.

43 Giddens, Anthony

44 Goffman, Erving

45 Kanter, R.M.

46 Schütz, Alfred

47 Berger, Peter L.
Outsiders: Estudios de sociología de la desviación

El capital. Una crítica de la economía política

La lógica de la acción colectiva

La división del trabajo social

Las reglas del método sociológico

Estudios de etnometodología

Asilos

El hombre político

La élite del poder

The logic of practice

Dependencia y desarrollo en América Latina

Clase y conflicto de clases en la sociedad industrial

Las consecuencias de la modernidad

Estigma

Men and Women of the Corporation

La fenomenología del mundo social

Invitación a la sociología

$\begin{array}{ll}9 & \mathrm{~T} \\ 9 & \mathrm{~T} \\ 8 & \mathrm{~T} \\ 8 & \mathrm{~T} \\ 8 & \mathrm{~T} \\ 8 & \mathrm{E} \\ 8 & \mathrm{E} \\ 8 & \mathrm{E} \\ 7 & \mathrm{~T}\end{array}$

$7 \quad \mathrm{E}$

$7 \quad \mathrm{~T}$

$7 \quad \mathrm{~T}$

$7 \quad \mathrm{E}$

$7 \quad \mathrm{E}$

$7 \mathrm{~T}$

$6 \mathrm{~T}$ 
Autor

48 Bourdieu, Pierre, y Passeron, Jean-Claude

49 Etzioni, Amitai

50 Glaser, Barney G., y Strauss, Anselm L.

51 Habermas, J.

52 Sorokin, Pitirim A.

53 Touraine, A.

54 Weber, Max

55 Weber, Max

56 Arendt, Hannah

57 Boudon, Raymond

58 Braudel, Fernand

59 Durkheim, Émile

60 Geertz, Clifford

61 Giddens, Anthony

62 Janowitz, Morris

63 Lazarsfeld, Paul Felix, y Rosenberg, Morris

64 Lukács, Georg

65 Mies, Maria

66 Nisbet, Robert A.

67 Thompson, Eric P.

68 Riesman, David

69 Schütz, Alfred

70 Simmel, Georg

71 Whyte, William Foote
La reproducción

Titulo

Votos

$T / E$

La sociedad activa

The Discovery of Grounded Theory

La transformación estructural de la esfera pública

Dinámica social y cultural

La producción de la sociedad

Sociología de la religión

La metodología de las ciencias sociales

Los orígenes del totalitarismo

La lógica de la acción social

Civilización y capitalismo

El suicidio

La interpretación de las culturas

Sociología

El soldado profesional

El lenguaje de la investigación social

Historia y conciencia de clase

Patriarchy and Accumulation on World Scale

La tradición sociológica

La formación de la clase obrera inglesa

La muchedumbre solitaria

Collected Papers

La filosofía del dinero

Street Corner Society
$6 \quad \mathrm{E}$

$6 \mathrm{~T}$

$6 \mathrm{~T}$

$6 \mathrm{~T}$

$6 \mathrm{~T}$

$6 \mathrm{~T}$

$5 \mathrm{~T}$

$5 \mathrm{~T}$

5 E

5 E

$5 \mathrm{~T}$

$5 \mathrm{~T}$

5 E

5 E

$5 \mathrm{~T}$

$5 \mathrm{~T}$

$5 \mathrm{~T}$

5 E

$5 \mathrm{~T}$

$5 \mathrm{~T}$

$5 \quad \mathrm{~T}$

5 E

$6 \mathrm{~T}$

6 T

Si nos centramos en los top ten encontramos en primer lugar, con casi 100 menciones y muy por delante de cualquier otro libro, Economía y sociedad, de Max Weber, libro publicado póstumamente en 1922 y que pasó casi desapercibido hasta los años cincuenta (de hecho, en los veinticinco años transcurridos desde su publicación hasta 1947 se vendieron menos de 2.000 ejemplares), pero que se ha transformado en el texto más influyente de la sociología moderna. Parece, pues, claro que si tuviéramos que elegir un solo libro representativo de la sociología del siglo XX según ésta es percibida por los sociólogos de comienzos del XXI, éste sería el resultado. No sorprende por ello que sólo Weber tenga dos textos entre los top ten, pues el cuarto lugar lo ocupa La ética protestante, con 47 menciones, sin duda una obra más discutible, pero aún más "emblemática» de la historia de la sociología y libro de lectura obligada en casi todas las licenciaturas de sociología del mundo entero ${ }^{3}$.

3 Sorprende, sin embargo, que La sociología de la religión, de Weber, obra sin cuya comprensión La ética protestante (de la que es sólo su primera parte) queda incompleta, y que fue el magnus 
El segundo lugar, pero ya a mucha distancia del primero (con sólo 59 menciones), lo ocupa un texto de combate y en cierto modo menor (y sin duda así se lo habría parecido a su autor), pero que tiene también un valor fetiche como inicio de la reacción crítica anticonservadora de la sociología americana: $L a$ imaginación sociológica, de C. Wright Mills, publicado en 1959. Si Weber puede ser considerado un representante de las "terceras vías» (ni marxistas ni anti-marxistas; volveré sobre ello más adelante), y Wright Mills es el primero de los sociólogos críticos americanos (próximo al marxismo, aun sin serlo), el tercer libro de la lista (ya muy próximo al segundo y con 52 menciones), Teoría y estructura social, de Robert K. Merton, publicado en 1949, reeditado en numerosas ocasiones y durante años el texto más citado de la sociología, representa una versión moderada del conservador funcionalismo americano, y ha sido libro de texto, y no ya sólo de lectura, para al menos tres generaciones de sociólogos. No sorprende, pues, que el texto clásico de Merton figure muy por delante del otro texto clásico y fundador del funcionalismo, La estructura de la acción social, de Talcott Parsons, publicado en 1937, una singular, original y forzada síntesis de los clásicos conservadores de la sociología (Pareto, Marshall, Durkheim y Weber, a quien da a conocer en América), para elaborar una teoría de la acción, y que sin duda es la obra que inaugura el ciclo moderno del pensamiento sociológico ${ }^{4}$.

Los tres primeros libros de la lista de la ISA exhiben así con claridad el alma politizada y escindida de la sociología moderna, que ha enfrentado durante casi todo el siglo a marxistas y anti-marxistas (representados estos últimos por el funcionalismo más radical de Talcott Parsons), para presenciar, a partir del giro lingüístico de 1968-70, el triunfo de las "terceras vías" políticas (el linaje de Weber-Mannheim-Elias) a lomos de teorías constructivistas. Y así, en el séptimo lugar aparece otro texto, como Economía y sociedad, también olvidado durante años: me refiero a El proceso de civilización, de Norbert Elias, publicado por vez primera en alemán y en Suiza en el año 1939, e ignorado por completo hasta su traducción al francés en 1972, momento en el que emergió como un clásico.

$\mathrm{Ni}$ es tampoco de sorprender que en el número cinco de la lista encontremos La construcción social de la realidad, de P. Berger y T. Luckmann, una excelente y sencilla síntesis entre el marxismo crítico de cuño lukacsiano, el interaccionismo simbólico de Mead-Blumer y la fenomenología, libro que inaugura un largo predominio (aún no cerrado del todo) de modelos interpretativos, hermenéuticos o constructivistas, publicado en 1966. En la misma línea de reacción frente al doblete marxismo-funcionalismo, que atrapó a la sociología durante

opus publicado en vida, aparece en los últimos lugares y con sólo seis menciones. Este sesgo dice mucho sobre las específicas «lecturas» realizadas sobre Weber y, singularmente, sobre el intento parsoniano de hacer de él un pensador anti-marxista. Volveremos sobre esto más adelante.

${ }^{4}$ El otro gran texto de Parsons, El sistema social, publicado en 1951, aparece también en la lista con 23 menciones y en el undécimo lugar. 
varias décadas, debemos incluir el texto del sociólogo canadiense Ervin Goffman La presentación del si mismo en la vida cotidiana, publicado en 1956 (pero ampliamente revisado en 1959).

Finalmente, y para completar los diez primeros, nos faltan dos versiones renovadoras del marxismo clásico, publicadas ambas alrededor de 1980, cuando el impacto del giro lingüístico comenzaba a ser asimilado. La primera es del francés Pierre Bourdieu, La distinción (1979), quizás la primera sociología de los sentimientos, una poderosa e inteligente síntesis entre el objetivismo durkheimiano y el marxismo hegeliano (típico de la sociología francesa, como lo es también un funcionalismo encubierto pero poderoso), y que encontramos en autores tan variados e influyentes como Althusser, Foucault o el mismo Baudrillard. Y, finalmente, la síntesis del heredero y epígono de la Teoría Crítica, Jürgen Habermas, La teoría de la acción comunicativa (1981), que recupera las teorías constructivistas del pragmatismo para la sociología crítica alemana.

Si evaluamos ahora en su conjunto las diez obras que los sociólogos de finales del siglo XX consideran más importantes de su historia reciente encontramos algunos interesantes rasgos comunes. Para comenzar, un claro predominio de textos teóricos sobre investigaciones empíricas. Si exceptuamos La ética protestante o, en otro sentido, La distinción, ambas investigaciones empíricas pero de altísimo vuelo teórico, la primera obra de claro contenido empírico aparece en el lugar 27 de la lista (La estructura ocupacional americana, de Blau y Duncan), pues los textos de Foucault (Vigilar y castigar), Beck (La sociedad del riesgo) o Moore (Los orígenes de la dictadura y la democracia) sólo con muchos matices pueden considerarse empíricos y, en todo caso, pertenecerían (como el propio texto de Merton, Teoría y estructura social) a una categoría mixta de teorías de nivel medio (middle-range theories las denominó Merton, su gran valedor). La última columna de la tabla recoge una codificación que he realizado del carácter teórico o empírico de las obras, aplicando este último calificativo con gran generosidad. Pues bien, aun así, sólo 22 de las 71 obras citadas podrían denominarse «investigaciones empíricas». Las restantes 49 , nada menos que el $70 \%$ aproximadamente, son teóricas.

A este sesgo teórico contribuye el peso marcado de la obra weberiana, pero se ve reforzado más aún si consideramos no los diez, sino los quince primeros textos, pues en el lugar undécimo aparece la obra clásica del fundador del interaccionismo simbólico, Espiritu, persona y sociedad, de George Herbert Mead, obra pensada a comienzos de siglo pero editada póstumamente por sus alumnos en 1934. En el duodécimo lugar, otro texto teórico de Talcott Parsons, El sistema social, de 1952, seguido de la obra más compleja de Durkheim, Las formas elementales de la vida religiosa; La constitución de la sociedad, de Giddens, y, finalmente, un libro que podría (pero sólo podría) considerarse una investigación empírica, El moderno sistema mundial, de I. Wallerstein.

Es más, sorprende que el texto que desde hace años es «el» modelo estándar de «buena» investigación sociológica, primera obra que combina y mezcla inducción y deducción, teoría e investigación, conceptos y datos, abordando un 
objeto de investigación "de nivel medio» (y que ha sido por todo ello considerado el equivalente en sociología a los Principia de Newton), y aludo, por supuesto, a El suicidio, de Emilio Durkheim, aparece en la lista, sin duda, pero en el lugar 59 y con sólo cinco menciones. Concluir por todo ello que la sociología moderna es ante todo teoría puede ser prematuro, aunque no insensato, pues el conocimiento no tiene como tarea reproducir la realidad, sino simplificarla, como nos recordaba Borges con su parábola de los Geógrafos Imperiales. Pero sin duda es cierto que los libros más influyentes en el trabajo de los sociólogos modernos, por recoger las palabras de la encuesta, son libros teóricos.

No sólo predominio de la teoría, sino de un tipo especial de teoría, la reflexiva, aquella que deriva de la sociología del conocimiento y cuestiona los propios supuestos desde los que pensamos. Pues a este campo más limitado pertenecen sin duda los textos citados de Wright Mills (primer libro de sociología de la sociología), de Berger y Luckmann (y no olvidemos que la primera edición de La construcción social de la realidad llevaba por subtítulo Una introducción a la sociología del conocimiento ${ }^{5}$ ), el de Bourdieu y, en no poca medida, los de Merton (fundador de la sociología de la ciencia) y Elias. Y ya en la segunda decena de clásicos encontramos el Durkheim de Las formas elementales de la vida religiosa (1912) y La estructura de las revoluciones cientificas (1962), de Kuhn, que, al romper con la ortodoxia epistemológica de la Escuela de Viena, abrió el camino a la más moderna sociología, no ya de la ciencia (como era la de Merton), sino del conocimiento científico.

Junto al peso de la teoría y de la sociología del conocimiento destaca, en tercer lugar, la fuerte presencia de la sociología europea, incluso mas allá del peso marcado de Weber. Sólo tres norteamericanos aparecen en los 10 primeros lugares (Wright Mills, Merton y Parsons) y sólo seis en los 20 primeros, lo que sorprende dado el peso de la lengua inglesa (y de la academia americana) en la conformación de la sociología del siglo XX. Sin duda, la orientación más aplicada y empiricista de esta sociología, fuertemente profesionalizada, podría explicar en parte esta escasa presencia, en todo caso sorprendente.

A destacar, en cuarto lugar, que buen número de los sociólogos más influyentes del siglo XX siguen vivos, lo que es todo un dato de la vitalidad actual de la sociología. Casi la mitad de los diez primeros viven aún y otros han fallecido muy recientemente (como Elias o Goffman). Y ya en prensa estas páginas se produce el reciente fallecimiento de Pierre Baurdieu. Contra la tesis extendida de la crisis profunda de la sociología contemporánea, el hecho llamativo es que buena parte de los sociólogos más influyentes de este siglo no son los clásicos, sino los modernos. En el último apartado de este trabajo intentaré construir una explicación de este distanciamiento de los clásicos.

Finalmente, debemos destacar el escaso peso de la sociología española o lati-

5 De hecho, es muy significativo este cambio de título pues vino a transformar lo que inicialmente era (y debió seguir siendo) un libro de sociología especial — la del conocimiento- en una teoría general, todo un indicador del "giro constructivista» de la sociología al que aludiré más adelante. 
noamericana. Sólo un español, Manuel Castells, con La cuestión urbana, aparece en la lista (con 4 votos y en el lugar 82$)^{6}$. Y el primer libro latinoamericano citado, de Cardoso y Faletto, Dependencia y desarrollo en América Latina, aparece en el lugar 41. Sin duda, ello puede deberse a sesgos en la propia muestra (aunque ese sesgo es también un dato a tener en cuenta), pero con todo es evidente el escaso relieve internacional de la sociología en lengua española.

Una vez inventariada la relación de libros más importantes de la sociología del siglo XX, tratemos de darle sentido histórico a los datos.

\section{LAS CINCO GENERACIONES}

Sin ánimo de hacer de ello una teoría general, podríamos resumir la historia de la sociología en los avatares de cinco generaciones de pensadores que podemos caracterizar con los rótulos respectivos de (1) pioneros, (2) fundadores, (3) institucionalizadores, (4) compiladores y (5) constructivistas, en el entendimiento que el término generación se toma aquí en el sentido lato y genérico de coetáneos y no en el estricto sentido mannheimiano de unidad generacional (aunque algunas de ellas sí podrían pasar el test mannheimiano). A estas cinco generaciones podrían añadirse quizás otras dos que se solapan ya con la contemporaneidad, y que analizaremos en los apartados finales de este trabajo.

Dejando fuera a los pioneros o inventores de la sociología (los nominalistas escoceses del XVIII o Montesquieu), que serían la primera generación, e incluso este calificativo sería excesivamente lato dada su extensión en el tiempo, la segunda generación es la de los fundadores, quienes escriben a comienzos o mediados del XIX y cuya figura más representativa es, sin duda, la de Augusto Comte, que inventará en 1824 el término "sociología» para sustituir el de "física social», sin duda más acorde con su orientación positivista pero que le había sido arrebatado por el belga Quetelet. Precedido por Saint-Simon y seguido por Tocqueville, Marx y Spencer (el más joven de todos pues, nacido en 1820, fallecerá en 1903), constituyen la segunda generación de sociólogos: los clásicos por antonomasia o fundadores, que, a diferencia de los primeros, son aún leídos y admirados. Aunque ciertamente no todos, y ya Parsons recordaba en 1937 que Spencer era tratado como un perro muerto. Saint-Simon y Comte llevan casi las mismas trazas a pesar de ser los ideólogos de la post-moderna sociedad del conocimiento. E incluso Marx puede seguir un camino similar, probablemente como reacción a la insólita fetichización que sufrió su pensamiento a partir de la segunda posguerra. Tocqueville, sin embargo, el gran analista de la democracia moderna, sigue siendo uno de los sociólogos más leídos, tanto en Europa

${ }^{6}$ La encuesta de la ISA se hizo bien poco después de la publicación de la trilogía de Manuel Castells La era de la información, que empezó a publicarse en 1996, y que ha tenido una impresionante acogida en todo el mundo. No tengo casi duda alguna que su repetición actual incluiría al menos este magnus opus del profesor Castells. 
como (sobre todo) en los Estados Unidos, y, al igual que le ocurre a Weber, el tiempo hace de él un autor más y más apreciado.

La tercera generación es la de los institucionalizadores, aquellos que llevan la sociología, hasta entonces un producto académicamente exótico, a la Universidad para hacer de ella una disciplina legitimada y aceptada. Son los Durkheim, Pareto, Weber, Simmel, Mead o Töennies, pero también los miembros clásicos de la Escuela de Chicago (A. Small, W. I. Thomas, Robert Park y Burgess), todos ellos académicos y profesores de universidad, lo que no fueron ni Comte (a pesar de sus muchos intentos por alcanzar puesto de profesor), ni Tocqueville, ni Marx, ni siquiera Spencer (que menospreciaba la universidad inglesa). Por el contrario, el primer departamento de sociología se creó en la nueva y liberal Universidad de Chicago en 1895, Durkheim fue el primer catedrático de sociología en Francia (en La Sorbona en 1910), Töennies es el primer presidente de la Asociación Alemana de Sociología en 1909, y Pareto es ya conocido profesor de economía en Suiza cuando publica el Tratado de sociología general, en 1916. Esta tercera generación fue consagrada como la de los «clásicos» de la sociología por antonomasia ya en los años cuarenta y cincuenta por la cuarta generación, la siguiente, y son por ello objeto de lecturas obligadas en la formación de cualquier sociólogo y ejemplos o modelos de buena sociología. Todos ellos nacen a mediados del XIX, comienzan a producir a finales de siglo y se agotan, física e intelectualmente, en los años inmediatamente posteriores a la Gran Guerra.

Así, si Comte muere en 1857 y Tocqueville dos años mas tarde, en aquel mismo año nacía Thorstein Veblen, dos años antes había nacido Töennies y un año antes Freud. Pero un año más tarde nacen Simmel, Mosca y Durkheim, y en la década de los sesenta nacerán Sombart, Thomas, Mead (ambos en 1863), Weber, Cooley y Park (los tres en 1864). De modo que podemos decir que la generación de los institucionalizadores nace justo cuando los fundadores están comenzando su periplo intelectual y, por lo tanto, se forman directamente bajo su influjo, ya sea el de Spencer en los norteamericanos, el de Comte en Durkheim, o el de Marx (y Nietzsche) en Weber. A su vez, esta tercera generación de sociólogos desaparecerá en los años anteriores o posteriores a la Gran Guerra y así, si en 1917 muere Durkheim, en 1918 lo hace Simmel, en 1920 fallece Max Weber y Pareto en 1923. Mead fallecerá más tarde, en 1931, pocos años antes de Töennies (1936) y de Freud (1939).

Como vemos, la Primera Guerra Mundial, que pone fin al optimismo decimonónico y al positivismo y es, por tantas razones, divisoria política y social entre el siglo XIX y el XX, lo es también en el terreno intelectual. Para entonces, la década de los veinte primero y la segunda posguerra después, emergía la cuarta generación, que es ya la central del siglo Xx, la de los compiladores, quizás la única que merecería con toda puridad el término de generación pues, ciertamente, es marcada a fuego por la terrible historia europea del siglo XX que, desde la revolución rusa y la Gran Guerra, y a través de los años veinte, la crisis del 29, la República de Weimar y el ascenso del fascismo, lleva a la Segunda 
Guerra Mundial, el Holocausto y la guerra fría. Como los institucionalizadores, también los compiladores habían nacido cuando la generación anterior comenzaba a publicar, a finales del XIX y comienzos del XX. En 1885 nace Lukács, en 1893 Mannheim (ambos, por cierto, en Budapest) y en 1898 nace Marcuse, figura emblemática del noventayochismo. Fromm nace en 1900, año en que muere Nietzsche y cuando Freud publica La interpretación de los sueños. Poco después, en 1902, nace Talcott Parsons, un año antes de que muera Spencer. Robert K. Merton nacerá en 1910 y, en 1916, Wright Mills. Para la década de los cuarenta estaban todos ya en pleno rendimiento, si bien los más jóvenes de ellos, como Lukács o Mannheim, habían comenzado a publicar ya antes, en la década de los veinte. En 1937, Parsons publicará La estructura de la acción social, un libro clave del funcionalismo y la sociología conservadora americana, y dos años más tarde su gran contrincante, C. Wright Mills, publica su primer artículo, por cierto de sociología del conocimiento. También en 1939, ya en plena guerra, se publica la primera edición de El proceso de civilización, de Nobert Elias. Sin embargo, el libro más citado y leído de la sociología del siglo XX, Teoría y estructura social, de Robert K. Merton, se publicará en una primera edición en 1949, ampliamente corregida y ampliada en 1968.

Los que estoy llamando «compiladores» saben ya que son sociólogos, y lo saben desde el principio, por formación o vocación inicial, cosa que ignoraba por completo la generación de los fundadores y sabía sólo a medias la de los institucionalizadores, que llegaron a ser sociólogos sólo al final de sus vidas. Son además, por supuesto, académicos y profesores todos ellos. Y por ello intentan muy conscientemente hacer de esta disciplina, ya legitimada académicamente, un saber científico riguroso, ya sea de orientación crítica o conservadora. Creen, pues, de una u otra forma, en una ciencia de la sociedad, y a todos ellos les une el objetivo de hacer de la sociología una ciencia. Y para ello, y éste es un segundo rasgo que les identifica, tratan de buscar las síntesis o las convergencias de corrientes diversas que les han precedido, ya sean síntesis de pensadores conservadores o de pensadores críticos. Los primeros, los conservadores, con Parsons a la cabeza, se apoyarán en el pensamiento europeo de Durkheim, Weber, Marshall y, sobre todo, el del último Pareto, con el claro y explícito intento de contrarrestar el avance marxista, muy marcado en Europa hasta 1968, pero también en los Estados Unidos a partir de la crisis de 1929. Es muy significativo en este sentido que La estructura de la acción social, la gran síntesis parsoniana del pensamiento europeo, publicada nada menos que en 1937, en pleno auge del fascismo, cita a Marx sólo de pasada y en menos de una docena de ocasiones. Los otros, los críticos, insatisfechos con la sociología «burguesa» pero también con el marxismo positivista de la segunda o la tercera internacional (el marxismo de Kautsky o de Bujarin), entroncarán a Marx con Hegel (y no con Kant, como los anteriores) para captar más tarde, desde la teoría de la cosificación de Lukács, la teoría weberiana de la burocratización del mundo e incluso el psicoanálisis de Freud. Hablo, por supuesto, de la Teoría Crítica de la sociedad elaborada por Adorno, Horkheimer, Fromm o Marcuse, un producto de la liberal y 
recién creada Universidad de Frankfurt que, más tarde aún, ya en la segunda posguerra, se desarrollará en el exilio americano.

Los años sesenta/setenta marcarán el fin de esta generación, sin duda la central del siglo XX. El primero en fallecer, en 1962 y aún joven, es Wright Mills, el solitario o maverick de la sociología americana, que más parece un personaje salido de las novelas de Jack Kerouack y los angry young man de los cuarenta que un académico respetable, lo que nunca llegó a ser en vida (jamás obtuvo la ansiada tenure, es decir, nunca llegó a ser catedrático). Pero es el fallecimiento de Parsons y Marcuse en 1979, con pocos meses de diferencia (en mayo y en julio, respectivamente), lo que simboliza el fin de toda una época del pensamiento occidental, y ciertamente de la sociología, la que iba a contraponer marxismo y anti-marxismo no ya como modelos científicos alternativos, sino incluso como concepciones del mundo y orientaciones personales. Pues, como veremos, la crisis del 68 va a afectar de manera importante a la intelectualidad europea y a la sociología, abriendo un camino muy distinto y aún no cerrado, el del constructivismo, que analizaremos posteriormente.

Pero 1979 es también la fecha en que Bourdieu publica La distinción, otro libro central de la sociología contemporánea. Y, siete años antes, Daniel Bell había publicado un libro pionero y de extraordinario impacto, La sociedad postindustrial, libro seminal que abrió el camino para la actual indagación de lo post-. Y con Bourdieu, Bell, Habermas, Coleman o Giddens (discípulo, por cierto, de Norbert Elias) entramos ya en la generación actual, de finales de siglo, la quinta (quizás sexta, como veremos) generación, la que ha recuperado la Gran Teoría para la sociología.

Esta breve cronología, si bien nos permite contextualizar los datos que examinábamos en el apartado anterior, no permite sin embargo percibir las grandes corrientes de pensamiento que marcan la sociología del siglo XX. Y, sin embargo, esas grandes corrientes se superponen como una envolvente al proceso biográfico descrito. Pues, como indicaba, también para la sociología el «corto siglo XX» de los historiadores comienza con la Gran Guerra para cerrarse en torno a la caída del sueño de la revolución rusa con la destrucción del muro de Berlín, en 1989.

\section{LA TENSIÓN CONSTITUTIVA DE LA SOCIOLOGÍA DEL SIGLO XX: ENTRE EL MARXISMO Y EL ANTI-MARXISMO}

Efectivamente, el período que va de 1918 a 1989, del fin de los Imperios y la revolución rusa a la caída del muro de Berlín, y que los historiadores han llamado el corto siglo XX o la "guerra civil de occidente», se caracteriza por la tensión marxismo y anti-marxismo, expresión en el pensamiento del predominio de la lucha de clases que adquiere su mayor virulencia en los años veinte y se prolonga, tras la Segunda Guerra Mundial, en la guerra fría que contrapone el bloque soviético al americano. Esta tensión política y social traspasa por com- 
pleto toda la producción sociológica, que se ajusta a la pauta del enfrentamiento entre quienes analizan el presente desde categorías marxistas o desde marcos (neo) positivistas, entre funcionalistas y marxistas, teóricos del consenso o teóricos del conflicto, contraposición que alcanza incluso al mismo nivel epistemológico como enfrentamiento entre un modo de argumentar dialéctico-crítico, de cuño hegeliano, y otro neopositivista-fisicalista, de cuño kantiano. La contraposición es de tal calibre que no estamos ante dos modos de hacer sociología, sino propiamente ante dos sociologías e incluso dos ciencias diversas y en conflicto. Y así, de una parte, el marxismo se transforma en otra sociología alternativa a la burguesa, con la que no tendría nada que ver, como podemos observar, por ejemplo, en el exitoso texto de Zeitlin Ideology and the Development of Sociological Theory (1968). Y, de otra, el funcionalismo pretende ser nada menos que el lenguaje de la ciencia social (la expresión es de Parsons), equivalente, pues, a la matemática como lenguaje de la física y la ciencia natural. Así, el funcionalismo no era una teoría social, sino el lenguaje mismo de toda teoría social, como dirá K. Davis.

No es casual que inmediatamente después de la Gran Guerra se publiquen dos de los textos más importantes para ambas corrientes, ambos gestados en las trincheras y desde Viena, la capital multicultural del viejo imperio austro-húngaro y verdadero laboratorio del pensamiento de entreguerras: Historia y conciencia de clase, de Lukács (1923), y el Tractatus Logico-Philosophicus de Wittgenstein (1922). Pues el primero marcará una profunda reorientación del marxismo abriendo el camino a la Teoría Crítica, mientras el segundo forzará el salto desde el positivismo decimonónico (en el que aún estaban atrapados Pareto o Durkheim) al neopositivismo del Círculo de Viena o de Berlín y el racionalismo crítico de otro vienés, Karl Popper, cuya obra fundamental, La lógica de la investigación científica, es de $1934^{7}$. El clásico debate de la sociología alemana entre los dos cabezas de ambas escuelas, Adorno y Popper, cuarenta años más tarde (en 1961 exactamente), reflejará con nitidez ese mismo contraste: teoría crítica marxista frente a neopositivismo funcionalista, dialéctica vs. analítica, conflicto $v$ s. consenso, sin conciliación posible. Nunca fue más cierto que tertium non datur, pues no estamos ante una simple confrontación de estilos de pensamiento o de escuelas, ni siquiera de "paradigmas» en el sentido de Kuhn (si es que tal cosa existe o ha existido en sociología), sino ante una confrontación radical de concepciones del mundo. Mi generación, la que se formó en la sociología en los años sesenta y setenta, española o no, aún se veía forzada a optar entre unos y otros. Por poner un ejemplo visible extraído de la sociología española, los títulos de cuatro de los más representativos textos clásicos de la sociología de esos años, todos ellos memorias de cátedra, muestran vívidamente ese contraste: La sociología cientifica moderna, de Salustiano del Campo, publicado en 1962, donde "sociología científica" equivale a funcionalismo positivis-

${ }^{7}$ Pero que todavía merece un lugar en la lista de mil libros de Montreal, con cuatro menciones. 
ta; La sociología, aventura dialéctica, de Luis González Seara, publicada en 1969, que apostaba desde el título por la vía "dialéctica»; Teoría sociológica; una introducción crítica, de Carlos Moya, de 1971, en el mismo sentido; y, finalmente, Sociología; entre el funcionalismo y la dialéctica, de Juan Díez Nicolás, publicado también en 1971, y cuyo título lo dice todo al tiempo ${ }^{8}$.

Un contraste que podemos visualizar mediante el de dos grandes escuelas, ambas coetáneas, y cuya influencia sigue siendo marcada. De una parte, la Escuela de Frankfurt, generadora de la Teoría Crítica, producto del liberalismo de esa ciudad en el marco agónico de la Alemania pre-nazi, y defensora de un marxismo renovado por relecturas de Hegel, Weber y Freud, y que sería alimento espiritual de la sociología crítica de los años cuarenta a setenta ${ }^{9}$. La dialéctica de la Ilustración, de Adorno y Horkheimer, publicada en la inmediata posguerra (1947), fue y es aún libro de lectura obligada (y así aparece en la lista con doce menciones). De menor actualidad hoy, aunque muy relevantes en su momento, fueron La personalidad autoritaria, de Adorno y colaboradores, o Dialéctica Negativa (que merecen sólo dos menciones), al igual que los diversos libros de Herbert Marcuse, Eros y civilización, Razón y revolución (con tres menciones) o El hombre unidimensional (que sólo obtiene una), publicado oportunamente en 1964 y que sería libro de lectura obligada del movimiento del 68.

Y, de otra parte, la Escuela de Columbia, generada en el marco vital de la ciudad de Nueva York como consecuencia de la colaboración de un teórico (Robert K. Merton) y un metodólogo (Paul Lazersfeld; otro vienés, por cierto), que habrían de elaborar la versión canónica (y aún actual) de los métodos de investigación sociológica: las entrevistas en profundidad y los grupos de discusión (focus group) como métodos cualitativos, y el sondeo de opinión pública (el survey) como método cuantitativo. Una investigación empírica que floreció en los Estados Unidos al hilo de la emergencia de mercados variados para sus productos: el mercado del marketing político con los sondeos de opinión, el mercado de los medios de comunicación de masas con la medición de audiencias, el mercado de los productos de consumo masivo en los supermercados (los fast moving consumer goods) con los test de producto o, finalmente, el mercado de la publicidad con los test de anuncios. La sociología salía, pues, de las aulas académicas, adonde había sido conducida por los institucionalizadores, para lanzarse al mercado profesional y llenar con su espíritu y sus productos la vida social, política y comercial. El sociólogo, un licenciado universitario más, deja de ser un intelectual crítico para pasar a ser un profesional que oferta sus servicios y cobra por ello.

${ }^{8}$ Incluso el clásico de Enrique Tierno Galván, Razón mecánica y razón dialéctica (Tecnos, Madrid, 1969), reincide en la opción.

9 A destacar que la escuela estructuralista francesa de los años sesenta y setenta ha dejado poca huella. Así, Lire le Capital, de Louis Althusser, aparece con sólo cuatro menciones, al igual que Poder político y clase social, de Nicos Poulantzas, libros ambos que, en su momento, tuvieron enorme influencia. La Antropología estructural de Lévi-Strauss o las Mitológicas del mismo autor merecen sólo dos menciones. 
La contraposición entre estos dos modos de entender la sociología fue de tal calibre que, en otros textos, he argumentado que unos y otros, marxistas y antimarxistas, se necesitaban mutuamente para existir pues difícilmente podía entenderse el funcionalismo sino como contraste y oposición al marxismo, pero también viceversa, era incomprensible el marxismo sino como crítica de la «sociología burguesa». Y así, su tensión (y debate mutuo) al tiempo disolvía (escindía) y constituía la sociología (y la ciencia social). Es la época que en $\mathrm{mi}$ libro La sociedad reflexiva (1990) llamaba del "consenso escindido" entre marxistas y anti-marxistas. Pues si la escisión fue y aún es claramente visible, también lo es el consenso profundo entre ambas escuelas que emerge ante un análisis más atento.

Efectivamente, no merece la pena detenerse a destacar lo mucho que les diferenciaba en sus presupuestos epistemológicos o en sus marcos teóricos. Baste señalar que si los marxistas remontaban las explicaciones a variables económicas (singularmente la dinámica de los modos de producción como generadores de la lucha de clases, verdadero motor de la historia), los funcionalistas, en la línea del primer Durkheim (el de La división del trabajo social) y de los antropólogos Malinowski y Radcliffe-Brown, harán de la cultura la variable independiente, entendida ésta como sistemas normativos ( $\mathrm{y}$ valores) de orientación de la conducta, al tiempo interiorizados (hacia adentro, en la estructura del carácter) e institucionalizados (hacia afuera, en expectativas recíprocas).

Pues más interesante es recalcar que la visibilidad y radicalidad de ese conflicto, central para la sociología del siglo XX y que se arrastra durante más de cincuenta años, alcanzando quizás su punto álgido en los debates del 68, oculta (ocultaba al menos) que ambos contendientes compartían sin embargo muchas cosas, y cosas muy importantes. Compartían en primer lugar la creencia en que una ciencia social es posible y deseable, algo simplemente evidente entonces (taken for granted, diríamos con el lenguaje de sus sucesores), pero que el tiempo pondrá en entredicho. Compartían en segundo lugar una fe, igualmente ingenua, en la racionalidad occidental como motor del pensamiento y de la historia; es decir, eran ilustrados y optimistas sin merma alguna y creían a pies juntillas en el universalismo de la razón. Con Helvetius, podían haber afirmado que tous les hommes ont un esprit également juste. Como los ilustrados, compartían además (en consecuencia) una filosofía de la historia entendida como proceso de modernización y de tránsito progresivo, pero inevitable, desde sociedades tradicionales, agrarias y rurales, a sociedades industriales y urbanas, que se expandía como una mancha de aceite desde el núcleo de occidente al resto del mundo. En resumen, unos y otros reflejaban (y contribuían a constituir, ambas cosas al tiempo) la historia de la expansión europea que, desde los Estados nacionales, y tras acabar con las peculiaridades locales internas (fueros, autonomías, lenguas), tarea cerrada a finales del siglo XIX, hace lo propio en el mundo entero a lo largo del Xx (imperialismo/colonialismo). El universalismo - ha señalado nada menos que S. P. Huntington en El choque de civilizaciones- es el preámbulo del imperialismo. Finalmente, para unos y otros, los sujetos de la 
historia mundial (y, por lo tanto, los objetos privilegiados de la ciencia social) son las naciones-Estado, marco indiscutible de las sociedades, de modo que cuando hablan de «sociedad» debemos entender (casi) siempre «sociedades estatalmente constituidas». Frente a ellas, frente a las «sociedades» (macro), los individuos son simples soportes pasivos de los procesos de «modernización», ya sean éstos vía democracias populares y planificación económica, o vía democracias formales y economía de mercado. Y ya sea en Bretaña o en Galicia (hacia adentro), o en Bolivia, Argelia o la India (hacia afuera).

\section{EL GIRO CONSTRUCTIVISTA EN LA SOCIOLOGÍA: DEL TRABAJO A LA COMUNICACIÓN}

El predominio de estos dos modelos (y de su contraste) empezará a quebrarse a mediados/finales de los años sesenta, y claramente a partir de 1968, que, tras la invasión soviética de Checoslovaquia y el descubrimiento del Archipiélago Gulag, lleva a la intelectualidad europea a romper con el mito de la liberación comunista, iniciándose así el fin de la guerra fría que llevaría a la caída del muro en 1989. Y quizás no es exagerado recordar que el movimiento del Mayo francés comenzó en un Departamento de Sociología (el de la Universidad de Nanterre) donde algunos de sus futuros líderes enseñaban esta disciplina (así, Daniel Cohn-Bendit) o eran discípulos de conocidos sociólogos (como Castoriadis o Touraine), y se difundió a través de los medios académicos occidentales apoyada por estudiantes y profesores de sociología (como Rudi Dutschke o la Facultad de CC. Políticas y Sociología de la Universidad de Madrid). Por lo demás, si a alguna de las que he llamado generaciones de sociólogos puede aplicarse con propiedad este término es, sin duda, a la del 68. Nacida al hilo de los acontecimientos descritos pero marcada por la revuelta estudiantil (y la matanza en la mexicana Plaza de las Tres Culturas) y la confrontación con la guerra de Vietnam, llevará como símbolos de identidad la exploración de nuevas formas de relaciones personales y sexuales, de las drogas y de la música rock, generando una estética propia que pronto se generalizaría. Se trataba, además, de una generación internacional, que respondía a los mismos símbolos en Madrid, París, Berkeley o Chicago.

En todo caso, y casi como por azar, en poco menos de tres años se publican los textos que serán punto de partida de poderosas nuevas corrientes: Exchange and Power in Social Life, de Peter Blau (1966); La construcción social de la realidad, de Peter Berger y Thomas Luckmann (1966); los Estudios de Etnometodologia de Harold Garfinkel (1967); se traduce, de Alfred Schutz, La fenomenología del mundo social (1967; la edición alemana, de 1932, había pasado también desapercibida); y, finalmente, El interaccionismo simbólico, de Herbert Blumer (1969). Textos todos ellos que inauguran nuevas corrientes (teoría del intercambio, etnometodología, fenomenología, interaccionismo simbólico), que colocan de nuevo al actor en el centro del análisis y a la cultura y la construcción social 
de la realidad (constructivismo) como procesos determinantes. Estamos, pues, ante el equivalente en ciencia social del "giro lingüístico" o hermenéutico de la filosofía que ocurre por los mismo años.

Libros que aparecieron precedidos por el ya citado de Goffman, La presentación del si mismo en la vida cotidiana (1959), o el de Peter Winch, The Idea of a Social Science (1958), que retoma al segundo Wittgenstein (el de los juegos de lenguaje) para la sociología. Y a los que podríamos sumar La lógica de la ciencia social (1967) o Conocimiento e interés (de 1969), ambos de Habermas, y que recuperan el pragmatismo americano para la sociología europea, o la segunda (y canónica) edición de Teoría y estructura social (de 1968), de R. K. Merton, que, desde el funcionalismo, lleva a éste mucho más allá de sus supuestos iniciales a través de la consideración de las consecuencias no intencionadas de la acción y de las predicciones que se autocumplen y autoniegan en ciencia social.

Al tiempo que esta renovación iniciaba el vuelo, se certificaba el fin del consenso escindido. Una de las grandes obras de sociología de la sociología, La crisis de la sociología occidental, de Alvin Gouldner, publicada poco después (en 1970) con el objetivo de analizar la situación de cambio e incertidumbre de la sociología, iba a certificar la crisis definitiva del funcionalismo, anunciando también la del marxismo. Y, un año más tarde, Norman Birnbaum certificaría la crisis del marxismo, que estallaba en mil orientaciones diversas. La metafísica del trabajo, acusación de Wright Mills contra el marxismo, resultaba ser el espejo de la producción (Baudrillard) donde todo se refleja y distorsiona, pero también el punto donde el marxismo dejaba de ser una filosofía crítica. Ir más allá del trabajo como actividad constitutiva del mundo (Habermas) era también ir más allá del marxismo.

Y nótese que si en los compiladores el peso de la sociología europea era aún dominante -incluso en el funcionalismo de Parsons o Merton-, éstas son corrientes marcadamente norteamericanas y, con mayor precisión, de la hiperliberal Costa Oeste, más que de la más europeizada Costa Este (de donde proviene el funcionalismo, producto del llamado "Círculo de Pareto», de la Universidad de Harvard). Dato espacial que, añadido al dato temporal (años sesenta y setenta), sin duda significativo también, ha permitido hablar de una sociología "de fumadores de marihuana» o de "sociólogos sin sociedad»; más adelante veremos por qué.

Las diferencias entre estas corrientes y las anteriores eran enormes, pero quizás la más importante es la siguiente. Marx había señalado que la ciencia se construye contra las apariencias, buscando la esencia detrás de ellas y, por lo tanto, como crítica de las ideologías. Y, en el mismo sentido, Durkheim había señalado que la ciencia se construye contra el sentido común. De modo que marxistas y funcionalistas, a pesar de sus muchas querellas, estaban también de acuerdo en que el camino del conocimiento menosprecia el modo como las cosas son captadas por el sentido común para ir — con afortunada frase orteguiana- «a las cosas mismas». Eran, pues, unos y otros, herederos de los "maestros de la sospecha», como llamó Stuart Hughes a los viejos maestros 
Nietzsche, Pareto o Freud, buscadores de la realidad latente y oculta por detrás de sus representaciones, meros síntomas a descifrar. Pues bien, frente a los intentos de captar la realidad tal y como es y sin adherencias ideológicas, las nuevas corrientes constructivistas descubren que lo importante no es cómo son las cosas (si es que son de algún modo), sino cómo son interpretadas, entendidas o construidas por los actores; lo importante no es, pues, «la situación» objetiva, sino la «definición (subjetiva) de la situación» pues, como señala el dictum de Thomas, si los hombres definen las situaciones como reales, éstas son reales en sus consecuencias, aun cuando la definición de la situación pueda ser irreal. Con ellos pasamos de los modos de producir la realidad a los modos de interpretar y construir la realidad.

Así, por poner algún ejemplo, Blumer afirma que los "mundos" que existen para los seres humanos están compuestos de "objetos"... y dichos objetos son el resultado de la interacción simbólica. P. Berger y Th. Luckman escriben que la lógica de las instituciones... no radica en la institución y funcionalidad externa, sino en el modo como son tratadas en la reflexión sobre ellas. Y, más enfáticamente, Schutz escribía: Bajo el término "realidad social" quiero entender la suma total de objetos y sucesos en el mundo social cultural según son percibidos por el pensamiento de sentido común de los hombres. Como escribió Peter Dreitzel, sintetizando esta perspectiva, desde el punto de vista del paradigma interpretativo (una categoría que subsumiría el interaccionismo simbólico, la sociología fenomenológica y la etnometodología ), la estructura social se basa en los procedimientos interpretativos de los miembros interactuantes de la sociedad... La realidad social en que la gente vive sus actividades cotidianas está construida no en los hechos "objetivos" de la situación, sino en las definiciones "subjetivas" de la situación... Bajo el paradigma interpretativo toda la realidad social es percibida como resultado de procesos de negociación en marcha.

Evidentemente, este cambio se debe a un cambio de orientación filosófica subyacente. Los anteriores, los compiladores, herederos claros del positivismo, eran materialistas y evolucionistas, mientras éstos son marcadamente idealistas. Marxistas y funcionalistas compartían una visión decimonónica y evolutiva del hombre y la sociedad; eran, de un modo u otro, darwinianos. $Y$, en ese sentido, ambos pensaban desde las necesidades y exigencias de adaptación del hombre al entorno o del entorno al hombre, de modo que conceptos como útiles, instrumentos o trabajo eran de uso ordinario. Pero los nuevos sociólogos van a pensar el mundo no en la homología del producir, sino en la homología del comunicar. El orden social no reposa en la producción e intercambio de objetos que son producto del trabajo humano, sino en el intercambio de mensajes. Por ello, si para los anteriores la realidad, social o no, era concebida como un mundo de cosas, para éstos es concebida como un mundo de símbolos o de representaciones. Los hombres viven en universos lingüísticamente estructurados y conformados, y la tarea de la ciencia social será de-construir esas representaciones, analizar cómo llegan a ser, de una parte, y cómo crean y producen la realidad misma, de otra. 
Ello genera una importante consecuencia metodológica: una marcada tendencia al nominalismo sociológico. Los anteriores, de nuevo marxistas o no, eran realistas y, con Durkheim o Marx, afirmaban que la sociedad es una cosa que tiene vida propia (aunque sea cosa d'une autre manière) y, por lo tanto, debe ser tratada como una cosa (son ambas afirmaciones del Durkheim de Las reglas del método sociológico). Éstos, por el contrario, dirán que la sociedad no es una cosa, sino un lenguaje que se construye en interacciones interpersonales que van dando sentido a las situaciones; es proceso, no cosa, e ideal, no material. Y así, si para los anteriores el individuo no era sino el soporte o la interiorización de relaciones sociales objetivas (el capitalista es capital personificado, dice Marx; el hombre es social, dice Durkheim), aquí la dinámica se invierte: la sociedad no es sino la exteriorización del sentido. Y si aquéllos adoptaban siempre la perspectiva macro de los grandes procesos históricos, situándose el sociólogo en el punto de vista del observador externo, éstos adoptarán una perspectiva micro y el punto de vista del actor, de modo que les interesa no tanto la sociología esotérica de la ciencia, sino la sociología etno de sentido común. Con lo que pasaríamos también desde métodos explicativos nomotéticos (es decir, apoyados en el descubrimiento de leyes sociales) a métodos comprensivos y hermenéuticos. Por decirlo de un modo gráfico, si para los compiladores marxistas o funcionalistas el concepto central de la sociología era el de "estructura», para los constructivistas el concepto central es el de «acción» y, conjuntamente, el de «sentido".

A mi entender, éste ha sido el giro crucial de la sociología del siglo XX que permite hablar de dos grandes períodos en su desarrollo ${ }^{10}$. El primero, desde la Gran Guerra hasta la crisis intelectual del 68, marcado por la contraposición entre izquierdas y derechas sociológicas; el segundo, a partir de la última fecha, reorientando la sociología hacia «la construcción social de la realidad», eslogan que hará fortuna. Todavía hoy, la lectura de cualquier catálogo de libros de las grandes editoriales de sociología permite descubrir que todo, al parecer, es construcción social: la mujer y el género, la prostitución o la raza, la clase social, el estatus o la delincuencia, la ciencia, la burocracia, el Estado, etc. Todo cuanto había sido descubierto como «cosa» pasa a ser de-construido y transformado en una forma nueva de «ideología». La superestructura, no la infraestructura, es determinante, pues no es el ser social lo que determina la conciencia, sino ésta la que determina el ser social.

A destacar, finalmente, que el debilitamiento del enfrentamiento marxismo anti-marxismo ha permitido el retorno de lo reprimido u oculto, el regreso de las «terceras vías» que se movían más allá de ese contraste y que habían sido

10 Para la sociología española, el giro constructivista puede muy bien ser representado por la publicación en 1978 del libro Teoría sociológica contemporánea, editado por José Jiménez Blanco y Carlos Moya, un funcionalista moderado y un crítico (que hacen las paces), en el que se presentan por vez primera a la sociología española el interaccionismo simbólico, la etnometodología, la fenomenología y la nueva teoría crítica. 
bien marginadas, bien simplemente olvidadas ${ }^{11}$. Sin duda, el caso más marcado es el de Max Weber y sus sucesores, Mannheim o Elias. Ya en vida, Mannheim había sido acusado de «marxista burgués», razón por la que fue rechazado por los marxistas (pues era burgués), pero también por los burgueses (pues era marxista), una contradicción que puede extenderse a los demás pues, de nuevo, tertium non datur. Entre nosotros, Ortega y Gasset, sin duda el pensador de mayor talento del siglo XX (y probablemente de los últimos siglos de pensamiento español), y cuya última obra fue de relevancia sociológica, fue estigmatizado igualmente como «liberal elitista», rechazado por la derecha por liberal y por la izquierda por elitista. Pero, sin duda, donde este retorno es más manifiesto es en el caso de Max Weber. Él mismo se autodefinió en cierta ocasión como discípulo de Marx y de Nietzsche, una mezcla sin duda explosiva. Pues bien, ese mismo linaje intelectual llevaría a Lukács a acusarle de "asalto a la razón» y a Parsons a malinterpretarlo como idealista, anti-marxista y teórico del consenso social. Sin embargo, Weber acabará siendo el sociólogo más influyente del siglo $\mathrm{XX}$, sin duda el único que (y sospecho que ésta es la razón de su éxito actual), apoyándose en su vastísima erudición histórica, pudo adoptar una "perspectiva histórico-universal», como gustaba decir, la perspectiva de la historia de la humanidad en su conjunto, viendo a Occidente desde fuera como uno más de los experimentos humanos y rompiendo radicalmente con el etnocentrismo eurocéntrico de la sociología.

Finalmente, no podemos olvidar que este giro lingüístico aparece sobredeterminado por una profunda crisis de la concepción heredada de la ciencia en general, y de la ciencia social en particular. Por supuesto, La estructura de las revoluciones cientificas, de Kuhn, libro que, desde la más pura ortodoxia neopositivista del Círculo de Viena (no en vano se publica en la Enciclopedia Internacional de la Ciencia Unificada), va a romper radicalmente con ella, iniciando una verdadera revolución científica, había sido publicado mucho antes, en 1962, y será determinante de una notable incertidumbre acerca del carácter de la ciencia, abriendo el camino no sólo a la sociología de la ciencia, sino a una variedad de modos de «hacer» ciencia.

Una incertidumbre que también se manifiesta en la propia sociología, que si en los años cuarenta a sesenta aparecía polarizada entre dos grandes esquemas, en los setenta y ochenta se nos presenta dividida en una pluralidad de orientaciones, escuelas y estilos, sustantivos y metodológicos, que se trasladan incluso a los temas u objetos de la indagación. Así, en 1987, Giddens y Turner podían constatar la proliferación de enfoques en el pensamiento teórico y la explosión de versiones rivales de teoría social, resultado de la incorporación de corrientes anti-

${ }^{11}$ A destacar el caso de Simmel, que, por méritos propios, debería ser incluido entre las terceras vías pero que, a diferencia de los anteriores, había sido objeto de atención por parte de la sociología americana (por la última Escuela de Chicago y a través de Louis Wirth) por sus trabajos sobre la vida urbana. En los años cuarenta y cincuenta, Simmel era así más conocido en Estados Unidos que el mismo Weber. 
guas que se habían marginado más el desarrollo de otras nuevas e incluso el mantenimiento remozado de algunas antiguas como el funcionalismo (en el neofuncionalismo de Alexander, por ejemplo) o incluso el marxismo (en el marxismo analítico de Elster, por ejemplo). La teoría sociológica contemporánea, concluían, se convierte en un conjunto variado y muchas veces confuso de enfoques. Es la época del florecimiento de las mil flores, en la que cada sociólogo cultiva su huerto (Salvador Giner) y en la que se podía escribir: ¿Qué es la sociología? Sociología es lo que hacen los sociólogos (Carlos Moya).

\section{EL REGRESO DE LA GRAN TEORÍA}

Los árboles impiden captar el bosque, y a medida que nos acercamos al presente falta distancia que permita objetivar el análisis. Llamo, pues, la atención del lector sobre esta duda del autor, que no sabe a ciencia cierta si el grupo del que ahora va a hablar, los nuevos teóricos, constituye una generación como las dos anteriores o es, más bien, la síntesis simple y la herencia de los constructivistas. Por edad, muchos de estos nuevos teóricos no son mayores que algunos de los constructivistas y, en todo caso, no puede decirse que el constructivismo ha sido sustituido por la nueva teoría, como sí fue sustituido el "consenso escindido" por el constructivismo y la nueva gran teoría. Es más, una buena parte de los sociólogos contemporáneos - especialmente los vinculados al poderoso movimiento de la sociología feminista - siguen siendo constructivistas y, en cuanto tal, críticos (y más frecuentemente críticas) acérrimos(as) de todo gran relato o narración, simple expresión del Gran Macho Blanco. Es más, me atrevo a pensar que los constructivistas, estos nuevos teóricos y los teóricos de lo post(a los que aludiré en el apartado siguiente), no son tanto tres generaciones temporales, sino más bien una y la mima que se focaliza alrededor de tres topoi o programas de investigación distintos: la de-construcción crítica del orden social, la creación de una teoría de lo social o el descubrimiento del misterio de la post-modernidad.

En todo caso, sí parece que el contraste manifiesto entre el poderoso realismo de los compiladores y el no menos poderoso nominalismo de los constructivistas originó en los años ochenta y primeros noventa (tenía que originar casi obligadamente) un vivísimo debate entre lo micro y lo macro, el nominalismo y el realismo, o la explicación y la comprensión, debate singularmente técnico y sin clara derivación política y ya superado, por fortuna, pero que ha sido muy fructífero en la construcción de la teoría sociológica. El resultado de este debate ha sido un poderoso retorno al tipo de Gran Teoría que se podría encontrar en las obras de Durkheim, Weber, Parsons o Adorno, sustituidas posteriormente por trabajos micro o de nivel medio.

Las obras más importantes de este retorno a la Gran Teoría, expuestas por orden cronológico, son quizás las siguientes: La distinción. Criterio y bases sociales del gusto, del francés Pierre Bourdieu, de 1979; la Teoría de la acción comuni- 
cativa de Jürgen Habermas, de 1981; El sistema social, de Niklas Luhmann, y La constitución de la sociedad, de Anthony Giddens, ambos publicados en 1984; y, finalmente, los Fundamentos de Teoría Social del norteamericano James Coleman, de 1990, el único aún no traducido al español. Todos ellos libros citados en lugares relevantes en la lista de Montreal: Bourdieu en el sexto lugar, con nada menos que 43 menciones; Habermas en el octavo lugar y con 29 menciones; Giddens en el 14, con 21; Coleman en el 23, con 11, y, finalmente, Luhmann en el 29, con 10 . Y nótese de nuevo, junto al dato de la unidad temporal (son textos todos ellos de los años ochenta-noventa), el dato espacial: el peso del pensamiento europeo, que regresa al primer plano, pues cuatro de los cinco lo son. Quizás podríamos añadir otro libro norteamericano, éste de Jeffrey Alexander, The Theoretical Logic in Sociology, una renovación del funcionalismo parsoniano, pero su menor influencia la pone de manifiesto su lugar en la lista de Montreal, con sólo cuatro menciones.

Más complejo resulta buscar la unidad de estos textos mas allá de la común búsqueda de un marco analítico global y general para la sociología, es decir, más allá de su común ambición teórica. Cierto que todos ellos tratan de tender puentes entre los dualismos heredados de las dos generaciones anteriores, singularmente la tensión entre estructuras y acciones, poniendo de manifiesto que, de una parte, las estructuras son las acciones y, de otra, las acciones son las estructuras, sin que haya primacía alguna en ese círculo o espiral por el que las acciones individuales reproducen (y son) las estructuras y éstas reproducen (y son) las acciones. Si los compiladores habían explorado la dimensión macro de la vida social, tomando como objeto a las sociedades estatalmente organizadas, y los constructivistas habían explorado la dimensión micro, tomando como objeto las interacciones lingüísticamente estructuradas, era lógico intentar una nueva síntesis que dé cuenta "de lo uno y lo otro». Y es, pues, lógico también que, en este proyecto, recuperen para la sociología al pragmatismo americano de Mead, Dewey o Pierce, no menos que la sociología comprensiva weberiana y la tradición historicista alemana (Dilthey).

Pero incluso estas afirmaciones, que valdrían por ejemplo sin matices para la obra de Giddens y, en gran medida, para la del propio Habermas, difícilmente serían aceptadas por los otros tres. Pierre Bourdieu, en la tradición estructural francesa que ha venido a añadir el objetivismo marxista sobre el durkeimiano (o al revés), es un realista contumaz para quien los sujetos o actores no hacen sino reproducir las estructuras, y ello incluso cuando parecen o se sienten más libres, como es en la sensibilidad y el gusto. Y aunque la enorme inteligencia de Bourdieu le permite al tiempo (y casi en cada frase) exponer, en primer lugar, los datos de la realidad (captada mediante encuesta o de otro modo), llevar a cabo, en segundo lugar, la interpretación sociológica de esos datos y, en tercer lugar, reflexionar sistemáticamente sobre los presupuestos epistémicos de esa interpretación (de modo que flexiona sobre la realidad y re-flexiona sobre la flexión), si su obra es apreciada por una mayoría de sociólogos es, más que por su inteligencia reflexiva, porque devuelve el peso a las estructuras ( $\mathrm{y}$ así también a las 
clases), confirmando el parecer de los clásicos, de modo que poco hay en él de construcción social de la realidad (hacia fuera) y mucho, por el contrario, de socialización e interiorización (hacia dentro). Algo similar podría decirse de la compleja y confusa, pero brillante, argumentación de Luhmann sobre la autonomía de los sistemas sociales, que recuerda sin duda al Parsons de El sistema social pero también, inevitablemente, a lo que sobre él escribía Wright Mills en La imaginación sociológica: una obra ciega a la semántica pero ebria de sintaxis y arquitectura, forma sin contenido. Finalmente, el texto de Coleman, también de una extraordinaria brillantez analítica, es el primer gran ejemplo de construir la sociología more economia, a partir del supuesto de actores racionales que maximizan la utilización de sus recursos, y es, por lo tanto y al contrario que los anteriores, una renovación radical del nominalismo vía homo oeconomicus.

De hecho, si analizáramos no los libros de teoría, sino los modos de pensar actuales de los sociólogos en cuanto tal, es decir, los procedimientos explicativos que utilizan a la hora de abordar problemas concretos, encontraríamos dos, y casi sólo dos, grandes esquemas que son, al tiempo, las dos grandes explicaciones del orden social previstas con precisión por Durkheim. En primer lugar, el utilitarista, basado en el supuesto del actor maximizador, un modelo que, desde los escoceses y Adam Smith, se extiende hasta la obra de Coleman o del premio Nobel Gary S. Becker, un esquema típico de la economía pero que se ha apropiado de parcelas sociales hasta ahora reservadas a los sociólogos (como, por ejemplo, la familia). El orden reposa aquí en la división del trabajo, la especialización que ella genera, y la interdependencia de sujetos que son distintos y se necesitan los unos a los otros; reposa, pues, en los intereses y sus entramados, de modo que el egoísmo es la base de la vida social. Es la solidaridad orgánica de Durkheim. Y, en segundo lugar, el esquema propiamente sociológico, la solidaridad mecánica de Durkheim, basada en una poderosa conciencia colectiva que asemeja a los individuos y hace que unos y otros interioricen una cultura (manifiesta en normas y valores) que ajusta las actitudes «espontáneas» (pero interiorizadas) de unos a las expectativas de los otros, y que explicaría no tanto cómo hacen lo que desean hacer, sino por qué desean lo que desean. Recordemos que si economistas clásicos (desde Pareto o Weber a Veblen) abandonaron la economía para pasarse a la sociología fue, justamente, porque aquélla explicaba los medios pero no los fines de la conducta. En todo caso, el debate entre modelos utilitaristas y modelos normativistas (que se prolongan en el moderno comunitarismo y republicanismo), entre el peso de la economía y el de la cultura, es más vivo que nunca.

\section{MÁS ALLÁ DE LO TRADICIONAL Y LO MODERNO: LO POST-}

Pensar, como decía Spencer-Brown, es trazar una raya en un espacio homogéneo, dividiéndolo, para poder luego comparar lo que hay a ambos lados. Pues bien, la sociología clásica se construyó alrededor de una de esas rayas, de una 
línea de demarcación nítida: la que separaba lo tradicional y lo moderno. La sociología describía el triunfo de la modernidad frente a la tradición y, por ello, toda la sociología clásica está pensada a partir de una cesura que contrapone las sociedades tradicionales a las modernas y trata de pensar ese tránsito. Es, pues, en definitiva, una teoría de la transición a la modernidad o, si se prefiere, una teoría de la modernización. Las dicotomías metafísico y positivo en Comte, feudal y capitalista en Marx, militar e industrial en Spencer, comunidad y sociedad en Töennies, estatus y contrato en Maine, solidaridad mecánica y orgánica en Durkheim, y así hasta las pattern-variables de Parsons, las salidas del «subdesarrollo" o incluso las "transiciones a la democracia», concebidas unas y otras como simples procesos de modernización. La perplejidad ante la emergencia de una nueva sociedad europea a partir del siglo XVIII fue la experiencia fenomenológica constitutiva de la indagación social, y así toda la sociología ha sido desde entonces una teoría de la modernización.

Ahora bien, la sociología no se limitaba a describir el tránsito a la modernidad pues ella misma, performativamente, contribuía a ese mismo tránsito. Lo describía, sin duda, pero lo impulsaba y legitimaba al tiempo, con lo que la modernidad era su punto de partida pero también su meta. No es casual, por supuesto, que la sociología se institucionalice académicamente antes en países no desarrollados que en los pioneros, pues en aquéllos cumple mejor su telos modernizador. Las primeras cátedras de sociología no se crean en Inglaterra, Alemania o incluso Francia, sino antes en España, Italia, Japón o Argentina (la excepción a esta regla son los Estados Unidos). Y ello porque la sociología se concebía no sólo (e incluso no tanto) como un reflejo analítico de la modernidad, sino como un instrumento en manos de las élites modernizadoras (y así, por ejemplo, en España son los krausistas quienes crean la primera cátedra de sociología, en 1898).

Pues bien, con el uso continuado del prefijo post- los sociólogos contemporáneos tratan de marcar una nueva línea de delimitación, una nueva cesura constitutiva, y así hablan de post-moderno, post-capitalista, post-burgués, postindustrial, post-emocional o post-fordista. Una actitud que parece sobredeterminar la más moderna sociología, con lo que estaríamos no ya en el siglo XX, sino en el amanecer del XXI.

Fue Daniel Bell, con El advenimiento de la sociedad post-industrial (1972), quien inauguró la moda, que, desde entonces, ha tenido numerosos seguidores: Risikogessleschaft, de Ulrich Beck, en 1986, quizás uno de los textos más creativos; Las consecuencias de la modernidad, de A. Giddens, en 1990; La sociedad post-capitalista, de Peter F. Drucker, en 1993, quizás el más desenfocado; la excelente síntesis del español Manuel Castells, La era de la información, de 1996-98; y, por supuesto, La condición post-moderna, de Lyotard (1986).

Con ello se quiere dar a entender que estamos, más allá de las sociedades modernas, ante un cambio nuevo e imprevisto que supone una segunda modernización, una modernización de la modernidad y, por lo tanto, una modernización reflexiva (Beck). Las sociedades actuales se des-tradicionalizan como lo 
hicieron las tradicionales, pero no de tradiciones «tradicionales», y valga la redundancia, sino de tradiciones modernas, las propias de la sociedad industrial y no las de sociedades agrarias. El cambio social afecta a lo ya cambiado y es, por ello, un cambio del cambio mismo. Y así, sabemos que instituciones esenciales que han sido la arquitectura de la sociedad moderna clásica están sufriendo cambios drásticos. La familia nuclear, que conformaba la vida privada y constituía la inmensa mayoría de los hogares, que salta en añicos; el trabajo (y la fábrica), que vinculaba al ciudadano con la colectividad y le otorgaba sensación de identidad a largo plazo en una carrera profesional o laboral, destruido en biografías singularizadas; el Estado-Nación, que se desarticula hacia abajo (en procesos de devolution), hacia arriba (en entes políticos transnacionales) y hacia adentro (en sociedades multiculturales); el orden internacional, que deja de ser un orden hobbesiano de Estados soberanos que se entienden en pie de igualdad (Schmitter) y en el que aparecen todo tipo de nuevos actores (instituciones multilaterales, empresas multinacionales, ONG, terrorismo internacional, etc.). En resumen, buena parte del entramado institucional de la sociedad moderna está sufriendo cambios brutales que la sociología contemporánea trata de captar, frecuentemente saltando desde modelos dicotómicos clásicos (tradicional/moderno) a modelos tricotómicos: de lo tradicional a la primera modernidad, una modernidad incompleta, en transición y todavía atrapada por las tradiciones «tradicionales». Y desde esta primera modernidad incompleta a la actual segunda modernidad, una modernidad triunfante, que realiza plenamente los ideales ilustrados y se asienta plenamente en la ciencia, la innovación, institucionalizando lo que para Kant era una novedad y una ruptura: Sapere aude. $\mathrm{O}$, por decirlo en un lenguaje más clásico, desde sociedades agrarias a industriales, y desde éstas a sociedades del conocimiento o la información. No estaríamos, por tanto, ante una sociedad post-moderna, sino más bien ante una modernidad radicalizada que, por ello mismo, hace emerger un horizonte utópico post-moderno. Si podemos pensar la post-modernidad es justamente porque nuestra realidad es ya plenamente moderna.

Pero el hecho de que aún no hayamos encontrado un término positivo que sustituya el post- negativo sólo indica que, si bien hay acuerdo en que estamos «mas allá» de las sociedades modernas (y ciertamente más allá de las industriales), no hemos sabido identificar el factor nuclear o constituyente de estas nuevas sociedades. Y así, si Bell (y, tras él, Dahrendorf y Touraine) la definía en función del tránsito de la industria a los servicios a causa de la primacía del conocimiento y la innovación, otros han destacado la información (más que el conocimiento) como eje integrador (así Castells) y otros, finalmente (como el propio Beck), revisando una tradición crítica de la racionalidad que debemos remontar a la Escuela de Frankfurt, hacen de la noción de riesgo el contenido positivo de lo post.

En todo caso, la experiencia de la post es, como siempre, previa a su captación en el pensamiento. Y aunque ello parece marcar el fin de una época social y de su modelización en el pensamiento, la época que contraponía tradicional y 
moderno, lo importante, sin embargo, no es sólo que haya una nueva realidad a pensar (global y no local) sino, sobre todo, que es necesario pensarla de otro modo. Así, se rompe el marco de referencia de las sociedades nacionales, que había sido el "objeto» privilegiado de la sociología: hacia arriba, en civilizaciones o sistema-mundo; pero también hacia abajo en culturas, estilos de vida y actores. De hecho, las tendencias extremas de esa dinámica teórica son ya bien evidentes. De una parte, un marco mundial sin sujetos: el mundo como pura red. Y, de otra, sujetos sin marco: actores racionales, el individuo desencarnado, abstracto. En todo caso, se problematiza lo que se daba por presupuesto: una teoría lineal de la modernización que, desde los centros universalistas (los Estados-Nación), se extiende y expande progresivamente sobre la barbarie localista y particularista.

Un proceso que no hace sino reflejar en el pensamiento el fenómeno de la globalización (la Segunda Guerra Mundial, por vez primera «mundial», y tras ella la creciente circulación de capitales, mercancías, mensajes y personas; el riesgo de catástrofe nuclear o ecológica mundial) que, en una historia que es por vez primera única, sitúa al individuo directamente frente al mundo. Lo que es tanto como decir: no somos ciudadanos de este o aquel país, somos ya ciudadanos del mundo, sin mediaciones. Y ello porque la frontera de Occidente, móvil y expansiva desde el siglo XV, ya ha tocado techo. No hay espacios en blanco en los mapas, no hay fronteras y no hay tierras vírgenes; las que quedan son más bien parques naturales artificialmente conservados dentro de una ciudad global. Occidente tenía un núcleo central y una frontera externa móvil; hoy tiene multitud de centros y no hay frontera, no hay un dentro y un fuera, ni en términos sociales (nada queda fuera de la civilización occidental-mundial, y lo que parece estar fuera no está fuera sino dentro, pero marginado) ni en términos naturales (la naturaleza no es un elemento externo al orden social, sino medio ambiente interno). Ni siquiera se sabe con precisión dónde cae la periferia. El viejo tercer mundo está ya dentro del primero (en los barrios de las áreas metropolitanas, en las aldeas de inmigración) y el primero ha saltado sobre el tercero (en las grandes urbes).

Ahora bien, una sociedad con fronteras (y más si éstas son móviles) puede exportar hacia afuera sus contradicciones (ya sean excedentes de población, de capital o de basura atómica); pero si no hay frontera todo queda dentro. De modo que la globalización tiene también sus consecuencias epistemológicas, pues si nada queda fuera es el fin real y efectivo, empírico, de las condiciones sociales que hacían posible la «metafísica por la ranura» (Adorno). Ya no podemos pensar que hay un afuera desde el que ver la sociedad pues ningún punto de vista es ajeno. Y si nada está fuera es porque no podemos separar el sistema del entorno; todo es sistema pues el entorno es interno.

Ello tiene al menos dos consecuencias epistemológicas. De una parte, el sujeto está dentro del objeto y no puede presumir que lo ve desde fuera, con lo que la temática de la reflexividad deviene central e inevitable. Cuando el observador forma parte de lo observado y lo ve desde dentro, entonces todo conoci- 
miento es autoconocimiento. Pero, además, todo autoconocimiento es acción, es modificar las condiciones de lo observado, y así la globalización acentúa las consecuencias no intencionadas. Todo incide en todo, nada está aislado, y la reflexividad sobre las consecuencias últimas de la conducta deviene una exigencia de la misma razón instrumental.

Pero con estos últimos comentarios salimos de la sociología del siglo XX para adentrarnos en el más incierto y proceloso mundo del presente y de la vanguardia de la sociología, terreno, pues, propicio para opiniones, sesgos o predilecciones personales. Dejemos, pues, que sean los sociólogos del futuro quienes puedan historiar (y eventualmente sociologizar) el pensamiento social del presente. Pues si alguna lección podemos extraer de este rápido repaso a un siglo largo de esfuerzos e ilusiones por entender el mundo social es que rara vez el presente se percibe a sí mismo de modo certero y con no poca frecuencia los éxitos del momento son fuegos fatuos que el tiempo acaba por enterrar. La experiencia precede siempre al conocimiento (¿podía ser de otro modo?) y éste, como la lechuza de Minerva, llega siempre tarde o, al menos, más tarde.

\section{BIBLIOGRAFÍA}

Tengo para mí que el mejor resumen de la teoría sociológica clásica sigue siendo el de Raymond Aron, Las etapas del pensamiento sociológico, que, sin embargo, se interrumpe con Weber, lo que también ocurre con el de R. Nisbet, La formación del pensamiento sociológico (Amorrortu).

Más actualizado y, sobre todo, más interesado en hacer sociología de los sociólogos (no en vano el autor es un conocido sociólogo del conocimiento) es el de Lewis Coser, Masters of Sociological Thought. Ideas in Historical and Social Context (Harcourt Brace Jovanovich, New York, 1977, 2. ${ }^{\text {a }}$ edición, e.o. 1971), lamentablemente no traducido al español. Y a quien le interese (como me ocurre a mí) la biografía intelectual de los sociólogos puede ver también T. Raison, Los padres fundadores de la ciencia social (Anagrama), y, por supuesto, algún diccionario como el de S. Giner, E. Lamo de Espinosa y C. Torres (eds.), Diccionario de sociología (Alianza Editorial, Madrid, 1998), y la excelente Enciclopedia Internacional de las Ciencias Sociales (Aguilar).

No es fácil encontrar el género de los readings en la sociología contemporánea y por eso (y por su calidad) llama la atención el libro de Josetxo Beriain y José Luis Iturrate (eds.), Para comprender la teoría sociológica (Verbo Divino, Navarra, 1998), en el cual encontramos una introducción y una selección de textos de todos los autores aquí mencionados.

Para una presentación de la sociología moderna puede verse el libro de A. Giddens y Turner (eds.), La teoría social, hoy (Alianza Editorial, Madrid, 1992), o el de R. Munch, Sociological theory from the 1850's to the present (Nelson-Hall, Chicago, 1994). Es interesante la visión de Félix Requena Santos en "Hacia una perspectiva reticular de la teoría sociológica» (Papers, 62, 2000, 
133-145). Y para un análisis más crítico puede verse N. Mouzelis, Sociological Theory: What went wrong? (Routledge, Londres, 1995). Un resumen sencillo pero lamentablemente simple (y, quizás por eso, exitoso) es el de George Ritzer, Teoría sociológica contemporánea (McGraw-Hill, Madrid, 1993).

Para lectores ya avezados y que deseen hacer un seguimiento más pormenorizado de estos temas teóricos, quizás lo más adecuado son los textos editados por el Grupo de Teoría Social de la Asociación Española de Sociología: E. Lamo de Espinosa y J. E. Rodríguez Ibáñez, Problemas de teoría social contemporánea (CIS, Madrid, 1993), y el de A. Pérez-Agote e I. Sánchez Carrión (eds.), Complejidad y Teoría Social (CIS, Madrid, 1996).

No debemos descartar, finalmente, el interés ni la importancia de los manuales de sociología, sin duda lo que más marca las «creencias» (en sentido orteguiano) del gremio. Actualmente, el más vendido es el de A. Giddens, Sociología (Alianza Editorial). Uno clásico es el de D. Martindale, La teoría sociológica; naturaleza y escuelas (Aguilar), pero podría citar no menos de dos docenas.

\section{ABSTRACT}

The $20^{\text {th }}$ century confirms the definitive institutionalisation (academic and scientific) of sociology as established public information, which is something that neither the pioneers of the $18^{\text {th }}$ century nor the great creators of the $19^{\text {th }}$ century (from Comte to Spencer, without forgetting Tocqueville or Marx) had achieved. Starting out from the data compiled by the ISA at its Montreal Conference, this paper aims at answering the question by using the most important sociology texts of the last century, taking advantage of these to establish a chronology of the development of sociological thought within the framework of a sociology of sociology. Examined here are the great institutionalisers of the early $20^{\text {th }}$ century and the compilers who, between 1920 and 1968, came to form two large schools (functionalist and Marxist), opposed to one another in many ways but converging in fundamental beliefs, and the constructivist or hermeneutical turn-around of sociology as from 1968 (which still prevails), and the subsequent return to the Great Theory that overlaps with the most recent analysis of society (industrial, bourgeois or modern). 